\title{
Investigation of the role of strategic management in enterprise knowledge management
}

\author{
Xiaobo JIA \\ Chongqing Youth Vocational and Technical College \\ Chongqing China,400712
}

\begin{abstract}
Strategic management needs the information of the external environment and competitor intelligence, which spawns competition and promotes its development. Competitive intelligence is always through strategic management process, it is always a major task for competitive intelligence to serve for the company's strategic decision-making, and strategic management has a natural close contact with competitive intelligence. This paper makes the statistical analysis and study of the case about knowledge management of Chinese enterprises in recent years, it describes the main contents of enterprise knowledge management research, and it summarizes the characteristics of enterprise knowledge management research and existing problems and proposes countermeasures to optimize business management research knowledge.
\end{abstract}

Keywords- strategic management; risks; business; Knowledge management

\section{INTRODUCTION}

Research shows that the more life-long enterprises, they are more aware of the importance of strategic management, however, those who have no goal and have never made the strategic management of the enterprise are rapidly being squeezed out of the market stage, as we can see, the strategic management is important for an enterprise. In recent years, Chinese enterprises have mushroomed emerging due to changes of systems and liberation of thought, it is necessary for them to introduce strategic management in order to make these companies on the virtuous track of sustainable development in the early stages of their creation. For an enterprise, what does strategic management have specifically effects on? First, strategic Management allows businesses to clearly understand themselves. Enterprise can not be as large enterprises and multinational companies with solid strength as to win the market because of limited strength, companies can give a clear positioning for themselves to determine their strengths and weaknesses through strategic management, so that, companies can avoid this situation, which they overestimate their own strength and a "breaks against" phenomenon in the market competition, on the contrary they also have the flexibility to maneuver in the market. Second, the strategic management can promote cohesion of employees and create a united business environment, and it retains key talent. For example, company determined to "do what others do not do" in the company early creation, and it taught the staff, although conditions are very difficult in the early days, but Sony employees have a sense of pride as to their own "career" engaging in, and we pushed only a few number of employees in small companies at the beginning to the giant multinational position with this in mind. Therefore, although the size of the business was not much, as long as the company's employees can work together to make progress, I believe that a small business will grow stronger one day, and strategic management just can play a catalytic role in this procedure. Third, we make a time frame for the successful development. Business leaders often put too much time on the management of daily affairs, they always think they do a lot of things every day, but they do not know where the target is. Strategic management can make a plan for the future development of enterprises, we develop a certain goal in each period, so business leaders can identify their own performance according to this plan and you can feel that you are getting closer and closer to achieve success. Fourth, the strategic management makes leaders in the middle and small enterprises remain a clear mind, and it corrects business deviations or improvement strategy in the course of strategy implementation.

\section{STRATEGIC MANAGEMENT FEATURES IN ENTERPRISE}

Although the strategic management is very helpful for business growth, but we must pay attention to that the strategic management has its own way in the implementation of the enterprise, if we ignore the features of strategic management, it not only does not receive the desired effect, but it will hinder the development of enterprises.

Formal degree of strategic management. For enterprises, formal degree of strategic management implementation is far less than large enterprises and multinational companies. If a company made the strategic decision-making process too formal, it will affect the business performance. Putting too much emphasis on structural, written business plan will make enterprises fall into dull stalemate, and because it reduces the flexibility that the enterprise depends on and survive. This is process of a strategic plan which will improve business performance, rather than the strategic plan itself. It demonstrates that business leaders (or business owners) who want their business to get development must focus on the specific implementation methods of strategic 
management, and they should keep strategy in their mind, but it doesn't mean that we put the strategy as a form to hinder flexibility, which should be flexibility in the use of strategic management. We have the ability and situations to use strategic management in the organizational structure and human resources until companies grow to a certain extent, then we make the strategy formalized.

Range of strategic management and competitive strategy. Companies generally operate in the single market or a limited number of markets to provide limited products and services. Therefore, the scope of its strategic business is smaller than large enterprises or multinational companies, namely the range of strategic management is small. This requires that small and medium sized enterprises should focus the strategic management on a the target point, they can not make comprehensive strategic management as the same with large enterprises and multinational corporations, ant they can only open up for the market step by step according to their own advantages. Unless it has special knowledge in the market or it can monopolize the market, otherwise, companies have to bear the enormous competitive pressures within the scope of its business, so the narrow range of strategic management decides that the competitive strategy is particularly important for companies, decision-making experience and personal qualities of business leaders (or business owner) have a great impact on the competitive strategy.

The degree of change in strategic management, For businesses, a problem is the management of growth, the growth rate of business creation generally exceeds those expectations range, while the growth of enterprises also means that the creator can not manage all the activity alone. Small and medium sized enterprises are generally private enterprise, partnership or limited liability companies, the American organization scientists found that their organization would experience five stages including growth process typically rely on innovation to grow, relying on the guidance of growth, relying on authorization to grow, relying on coordinated growth, relying on cooperation to grow, the growth dynamic is different at every stage, so there will be different management issues, but strategic management will be also constantly changing with the development of enterprises.

\section{CONSTRUCTION OF ENTERPRISE KNOWLEDGE} MANAGEMENT SYSTEM

The fundamental purpose of enterprise knowledge management system is to improve the knowledge of the whole enterprise and each employee's ability to obtain knowledge, organization of knowledge and innovation capacity, it puts the people, work, business, social environment to a whole through the integration of information technology to provide the necessary technical environment for the modern enterprise knowledge management. According to this, I believe that enterprise knowledge management system can be composed by Enterprise Competitive Intelligence Management System (3I), enterprise information management platform (TPI) and corporate multimedia web conferencing platform (TNC).

1 Enterprise information management platform (TPI). TPI is a large-scale intelligent content management platform based on unstructured document management. The platform consists of enterprise resource management systems, enterprise resource processing systems, corporate publishing and searching systems, enterprise decisionmaking advisory system, competitive intelligence gathering system, internal training systems and employee's digital library systems. It takes FTS as the core and uses the popular B / S browser retrieval methods and advanced three $\mathrm{C} / \mathrm{S}$ architecture, it can make the enterprise search a variety of information, technical documentation, and financial statistics through a unified search interface. It can simultaneously manage text, images, multimedia and other information to support dynamic web publishing. Whereby companies can establish a variety of distinctive internal knowledge base, employees can exchange knowledge, learn knowledge and share knowledge through the platform.

Competitive Intelligence Management System, Enterprise Competitive Intelligence Management System 3I (Internet Information Integration) is a powerful network information analysis, management and publishing tool. Many small and medium sized enterprises are often at a loss with facing enormous internal information management and information flow and data flow, and 3I system can automatically collect information in which user are interested from the Internet, after the integration of intelligent processing, and it provides the users with the personalize form. The system is capable to rapidly and timely capture user needs about all kinds of news, information science and technology, market trends, policies and regulations and so on. It can be widely used in information monitoring, intelligence gathering, market tracking, and information security inspection and filtering applications.

Multimedia enterprise web conferencing platforms (TNC).TNC is based on network communications platform, which is a visualization of office management systems used in a variety of network environments and. The system integrates the world's advanced computer network technology and multimedia technology, communications technology, and it has many application functions including video transmission, audio, interactive whiteboard, application sharing, text chat, shared resource synchronization, replay of conference control level management, server cascaded to support multiple conferences, remote camera control, multi-point video automatically switches browsing. It can provide an interactive virtual scene for teleconferencing, collaborative work, staff training and other activities in large and medium-sized enterprises to achieve exchange and sharing of knowledge and information of business intelligence, as well as it can save funds for corporate meetings, transportation costs, and improve efficiency. 


\section{ENTERPRISE KNOWLEDGE MANAGEMENT PROBLEMS}

Looking at recent studies of enterprise knowledge management, I believe that there are the key issues as following:

Heavy theory, light practice. At present, the research on the majority of enterprise knowledge management focuses on theoretical research, the real results of research on enterprise knowledge management practices are not much. Most of the existing research is to study the macrolevel, and it has relatively small micro-level studies, and this situation is not conducive to the further study of enterprise knowledge management. Who study in business management knowledge are now researchers and teachers in College, Faculty and research institutions, and who expose to the real business about the enterprise knowledge management practices are seldom. Of course, it is still relatively to backward enterprise knowledge management practice in country itself.

Imbalances in research institutions and regional team, At present, who are engaged in enterprise knowledge management research in China are mainly teachers and researchers in university hospital, and research institutions of the department, but the real business is very small and it is only $4.66 \%$, the structure of research team is not conducive to a better knowledge of high level of development about business management, and it is likely to cause the disjunction between theory and practice. In addition, regional distribution of the enterprise knowledge management research team is uneven, and the region of the western proportion is lower.

The study of foreign enterprise knowledge management is rarely. Yet few people make research about foreign countries, especially for enterprise knowledge management in developed countries. In the 322 papers retrieved, only three articles are related to foreign enterprise knowledge management research, which accounts for only $0.93 \%$.

\section{CORRESPONDING COUNTERMEASURES}

Strategies to optimize knowledge management research, the one is that we must expand research in the field in the study of one enterprise knowledge management, we take enterprise knowledge management practices as a focus of the study with the existing theory to guide the practice of knowledge management, so that we unify the theory and practice. At present, especially we study various types of enterprises knowledge management model combined with the specific situation of China's enterprises. The second is to strengthen the study of the problem of enterprise knowledge management system, the risks of knowledge management systems, organizational behavior, the risks of knowledge management, enterprise knowledge management capabilities, enterprise knowledge management measure, enterprise knowledge management implementation and so on in the new situation, these aspects should be a hot issue of the study of knowledge management of Chinese enterprises in the coming years.
Third, we should pay attention to the study of foreign enterprise knowledge management, and we actively learn from the results of studies of foreign companies. Enterprise knowledge management research in China started relatively late, the gap is still large when we compared with developed countries, and therefore, in the study of knowledge management theory and practice, we should actively learn from existing research results in developed countries, we track the world's knowledge of business management studies trends, focus on enterprise knowledge management research hotspots and cuttingedge issues to improve the overall level of corporate knowledge management research. The fourth is to broaden the research team of enterprise knowledge management, particularly business professional in company should actively be involved in the study of the theory and practice about knowledge management in the past, we study with their own knowledge management practices, so that our enterprise knowledge management can change from the macro level to the micro level to promote research of enterprise knowledge management theory and practice of developing into the depth direction. The five is that western scholars should actively involve to the study of knowledge management theory and practice in an effort to raise the level of research knowledge management in western China, and promote the competitiveness of enterprises in the western region.

\section{CONCLUSIONS}

In summary, we can see that corporate strategy itself can be as a means to avoid the uncertainty risk caused by the future development, and it continue to develop and evolve with the changes in the environment, while the risk of the strategy itself is also increasing from the appearance of strategic problems and content of the strategic management theory. From the background of strategic problem to rise and strategic problem-solving approach perspective, the root of strategic risks arising is because of changes in the environment, which leads that the degree of matching business opportunity resource capacity and environmental declines, and unable to achieve profitability goals. Therefore, the matching of enterprise resource capacity and environment face significant deviation affected by uncertain factors, and that corporate strategic objectives can not be achieved is inherent causes to produce strategic risks. Company as an open system, needs information with the environment and energy exchange, it needs to realize the value of goods or services in the environment, whether strategic concept are made or not, business objective requires that products should match with market demand! Under the Normal circumstances, this matching is driven by the pressure of the external environment and internal growth momentum to keep a dynamic balance. 


\section{References}

[1] Liu Qin. Strategic Enterprise Management Deficiency and Coping Strategies [J] SAR economy, 2010, 05: 244-245.

[2] Shang Yingqiu. Evolution of corporate strategic management theory and Analysis of strategic risk Thought [J] Technology \& Management Research, 2011, 03: 65-69.
[3] Hu Yifan. Evolution of strategic management and Research on Competitive Intelligence [J] Modern intelligence, 2007, 11: 34-37.

[4] Li Juan. The construction of knowledge management system [J] Library Science, 2005, 08: 96-98.

[5] Cheng Qihui. Progress in the study of knowledge management for Chinese Enterprises [J] Intelligence magazine, 2005, 11: 97-99 + 102 